\title{
Governança no setor sucroalcooleiro: uma análise comparada de São Paulo e do Cerrado Mineiro e Goiano
}

\author{
Governance on the Brazilian sugar-ethanol sector: a compared analysis of São Paulo and \\ Cerrado States of Minas Gerais and Goiás
}

\author{
Cristiane Feltre ${ }^{a}$ \\ Bruno Benzaquen Perosa ${ }^{b}$
}

\begin{abstract}
Resumo: O objetivo deste artigo foi comparar as formas de governança no abastecimento de cana-de-açúcar nos principais estados brasileiros produtores (São Paulo, Goiás e Minas Gerais). A pesquisa foi desenvolvida a partir de metodologia quantitativa e qualitativa, com base em dados secundários e revisão bibliográfica. Os resultados mostram que, ao longo do tempo, o abastecimento de cana sofreu algumas alterações nos principais estados produtores que podem ser explicadas pelas mudanças na estrutura regulatória, pelo perfil e organização dos produtores e pelo perfil gerencial das usinas. No caso das regiões do Cerrado goiano e mineiro, observou-se no início da expansão canavieira um processo de maior integração das usinas (maior proporção de cana própria) devido à falta de fornecedores nessas regiões. Contudo, esse processo vem se revertendo à medida que muitos agricultores de outras atividades inserem a cana em suas propriedades e passam a se organizar em associações para gerir a produção e comercialização com as usinas.
\end{abstract}

Palavras-chave: Governança; Desregulamentação; Fornecimento de cana-de-açúcar; Expansão Canavieira.

Classificação JEL: Q13; L23

\begin{abstract}
This paper aimed to compare the governance mechanisms used for sugarcane transactions on the main Brazilian producer states (São Paulo, Goiás e Minas Gerais). The research was developed based on quantitative and qualitative methods using secondary data and bibliographic review. Results revealed many transformations on governance mechanisms used on supply strategies on producer states, which can be explained by regulatory changes, for organization and profile of cane producers and mills managerial profile. In the Cerrado mineiro and goiano regions, it was observed that on the beginning of the cane expansion on the 2000s more integrated governance strategies were adopted by mills (higher share of own cane) due to the lack of suppliers on these areas. Although, this trend is changing on the last years since many farmers are planting cane and getting organized to produce and trade their supply with mills.
\end{abstract}

Keywords: Governance; Deregulation; Sugarcane Supply, Sugarcane Expansion.

\footnotetext{
a Pontifícia Universidade Católica de Campinas. E-mail: cristiane.feltre@puc-campinas.edu.br

${ }^{b}$ Instituto de Economia e Relações Internacionais - Universidade Federal de Uberlândia. E-mail: brperosa@ufu.br
} 


\section{Introdução}

O setor sucroenergético representa uma das mais importantes cadeias produtivas do agronegócio brasileiro. Esse setor é parte da história da agricultura brasileira e suas origens remontam à época das capitanias hereditárias, em que a cultura canavieira assumia papel central na ocupação da região Nordeste do país.

Ao longo do último século, a atividade canavieira foi assumindo novas configurações e se expandindo por diferentes regiões do território brasileiro, com uma maior expansão pela região Sudeste brasileira. A partir da Segunda Guerra Mundial, o estado de São Paulo se tornou a principal região produtora no país, sendo responsável em 2017 por 59\% da produção nacional (IBGE, 2018).

Apesar de São Paulo ainda representar a maior parte da produção brasileira de açúcar e álcool, a partir do início da década de 2000, novas regiões produtoras começaram a se estabelecer, especialmente na região Centro-Oeste. Tal produção passou a disputar espaço com grãos nas regiões de Cerrado, o que vem demandando adaptações tecnológicas e organizacionais no modelo de produção de etanol que vigorava no estado de São Paulo.

A região do Cerrado é bastante extensa, havendo diferentes definições para o território abrangido por tal bioma. Assim, o presente estudo analisará duas unidades da Federação que compõem parte do Cerrado brasileiro, em que a cultura da cana-de-açúcar se expandiu ao longo da década de 2000, a saber: Goiás e Minas Gerais. O estado de Goiás possui como bioma principal o Cerrado e alguns trechos de Mata Atlântica (GOIÁS, 2019). Já, no estado de Minas Gerais, a cobertura vegetal é formada por três biomas diferentes: Cerrado, Mata Atlântica e Caatinga. O Cerrado está presente nas regiões Oeste e Noroeste do estado (MINAS GERAIS, 2019).

Essas duas unidades da Federação (UFs) ocupam a segunda e a terceira posição na produção de cana-de-açúcar, respectivamente. Entre 1990 e 2015 a produção de Goiás passou de $2,5 \%$ para $9,1 \%$ da produção nacional, enquanto a produção mineira foi de $7,0 \%$ para $8,9 \%$ (IBGE, 2018).

Do ponto de vista tecnológico, a principal inovação adotada nessa nova fase de expansão está relacionada à mecanização da colheita, que alterou o modelo de corte manual que vigorou no setor ao longo de sua história. Apesar da motivação para essa inovação estar ligada à questões ambientais (redução das emissões de gases poluentes devido a não necessidade de queima da cana que era necessária para o corte manual) e econômicas (barateamento das máquinas e maior dificuldade de conseguir trabalhadores rurais a um custo viável), as novas áreas de expansão no Cerrado apresentaram também vantagens para a mecanização, em razão do terreno mais plano.

Nas questões organizacionais e de gestão das usinas também se observaram mudanças importantes, especialmente com relação a forma de abastecimento de matériaprima. No estado de São Paulo, sempre vigorou um modelo em que havia uma maior separação entre a produção e o processamento da cana. Nas novas regiões, o setor se estabeleceu com um maior grau de integração vertical, predominando a chamada cana própria (terras próprias ou arrendadas pela usina) ou contratos de parceria entre produtores 
e usinas. Essas diferenças podem ser explicadas tanto por questões do ambiente institucional quanto pelo perfil dos agricultores que entraram na atividade.

Dessa maneira, observa-se que a expansão da cana-de-açúcar no Cerrado brasileiro ocorreu a partir de um modelo de produção distinto daquele que dominou as regiões mais tradicionais, como o estado de São Paulo. O presente artigo se propõe a analisar a evolução da produção canavieira nessas regiões, com especial atenção às formas de governança utilizadas para o abastecimento das usinas. Dentre essas se encontram regiões tradicionais, formadas no período de regulação estatal até o início da década de 1990, e novas regiões produtoras, estabelecidas após a desregulamentação setorial nos anos 2000.

$\mathrm{O}$ artigo está dividido em quatro seções, além desta introdução. Na seção 2, é apresentada a revisão bibliográfica, dividida em uma seção de revisão teórica seguida de uma subseção de revisão histórica acerca do setor sucroalcooleiro brasileiro. Na seção 3, é explicada a metodologia do trabalho, que mostra a caracterização dos dados e das áreas a serem estudadas e o método de análise. Na seção 4, trazemos a discussão dos resultados, começando por uma análise das principais regiões produtoras em cada estado e em seguida uma análise da evolução nos mecanismos de governança para o fornecimento de cana em cada estado. Por fím, na seção 5, abordamos as principais conclusões e resultados do trabalho.

\section{Revisão da Literatura}

\subsection{Ambiente institucional e governança: uma perspectiva teórica}

Neste sentido, a atuação do Estado sobre os setores econômicos, representam uma das principais dimensões institucionais a serem consideradas. Setores sobre forte regulação estatal tendem a apresentar reduzida interação entre os agentes econômicos (AZEVEDO, 2000). O papel de intermediação estatal pode afetar tanto os instrumentos utilizados para coordenar as transações quanto outras formas de organização setorial que tendem a ser desestimuladas.

A literatura da Nova Economia Institucional (NEI) explora as interações entre as estruturas de governança, mecanismos utilizados para coordenar as transações, e o ambiente externo à organização, o chamado ambiente institucional. Para um dos mais importantes ramos da NEI, a chamada Economia dos Custos de Transação (ECT), as estruturas de governança seriam parte de uma estratégia de minimização de custos de transação e busca por eficiência (WILLIAMSON, 1985). Nesta perspectiva, os agentes econômicos buscam estruturas que minimizem seus custos, considerando especificidades da transação e do ambiente institucional em que estão inseridos.

Outras abordagens institucionalistas, como a sociologia econômica, não defendem que as formas de governança sejam predominantemente definidas pela eficiência ou custo de transacionar, mas ressaltam o papel das relações de poder nas formas de coordenação observadas (GRANOVETTER, 2005; DIMAGGIO, 1990). Assim, o ambiente institucional em que se estabelecem essas relações, teria papel central na definição das 
instituições do mercado que coordenam as relações econômicas e sociais (FLIGSTEIN, 1996).

Desta forma, pode-se considerar que grande parte das abordagens do chamado novo institucionalismo (SCOTT, 1995) ressaltam a relação entre ambiente institucional e governança. Alguns autores (GREIF, 2006; AOKI, 2001) exploram o impacto de mudanças institucionais nas estratégias dos atores, ressaltando que, mesmo após mudanças abruptas, instituições mantêm uma dependência de trajetória (path dependence) com relação ao ambiente institucional anterior (NORTH, 1990).

Diante das profundas mudanças institucionais que se observou nas cadeias agroindustriais brasileiras no início dos anos 1990, notou-se igualmente transformações nas formas de governança dessas cadeias. Isso ocorreu especialmente nas cadeias agroindustriais que sofriam forte controle estatal (café, cana-de-açúcar, trigo, entre outras), em que as transformações profundas no ambiente institucional acarretaram mudanças nas estratégias de governança (FARINA; AZEVEDO; SAES, 1997; BELIK, 1992; SHIKIDA; PEROSA, 2012).

O controle exercido por agentes públicos nas cadeias agroindustriais tinha impacto direto sobre a organização das cadeias, bem como das estratégias adotadas pelos agentes privados. No que tange ao ambiente organizacional, a redução do papel do Estado na coordenação das cadeias, gerou mudanças e novidades na organização setorial, tanto no que tange à coordenação vertical (entre diferentes elos das cadeias) quanto horizontal (no mesmo elo).

$\mathrm{Na}$ coordenação vertical, especialmente nas relações entre compradores e fornecedores, observaram-se novas formas de relacionamento, com contratos customizados para tornar as transações mais eficientes. Logo, o setor sucroalcooleiro tornou-se um dos que apresentam a maior variedade de contratos, que vão desde a simples compra de matériaprima até o arrendamento de terras para produção de cana própria (CONEJERO et al., 2008; PICANÇO FILHO; MARIN, 2012).

No que tange a coordenação horizontal, observam-se variados acordos setoriais coordenados por entidades de classe. Como explorado por Belik, Paulillo e Vian (2012), a formação de conselhos setoriais foi uma importante tendência nos complexos agroindustriais brasileiros nos anos 1990, estabelecendo novas formas de coordenação no setor.

Assim, observa-se que mudanças no ambiente institucional suscitaram a emergência de novas formas de coordenação vertical e horizontal nas cadeias agroindustriais brasileiras. Contudo, observa-se que regiões que se formaram no período de regulação estatal mantêm algumas características, mesmo após as transformações observadas no ambiente institucional, particularmente no período após a liberalização nos anos 1990.

\subsection{Regulação e Governança no Setor Sucroalcooleiro}

Assim, observa-se que mudanças no ambiente institucional suscitaram a emergência de novas formas de coordenação vertical e horizontal nas cadeias agroindustriais 
brasileiras. Contudo, observa-se que regiões que se formaram no período de regulação estatal mantêm algumas características, mesmo após as transformações observadas no ambiente institucional, particularmente no período após a liberalização nos anos 1990.

A intervenção do Estado na cadeia produtiva de açúcar e álcool já se mostrava presente no período colonial (VIAN; BELIK, 2003). Segundo Ramos (1999), essa intervenção se aprofundou nas primeiras décadas do século XX, com a criação do Instituto do Açúcar e Álcool (IAA), em razão dos conflitos entre usineiros, pequenos fornecedores e trabalhadores rurais.

Uma das medidas que objetivavam reduzir os conflitos e disciplinar as relações entre produtores de cana e usinas, foi promulgado no Estatuto da Lavoura Canavieira em 1941 (BRASIL, 1941). Uma das regras estabelecidas pelo Estatuto e que moldou parcialmente as estruturas de governança no abastecimento de cana naquele período foi a determinação das cotas de fornecimento, na qual a quantidade de cana própria da usina poderia chegar a $60 \%$ no máximo e os $40 \%$ restantes de fornecedores externos, com preços fixados pelo IAA.

Uma das determinações que, segundo Ramos (1999, p. 97), "nunca passou de letra morta" dizia respeito ao fato de que as usinas que já possuíssem mais de $40 \%$ de cana abastecida por fornecedores externos não poderiam reduzir essa participação, assim como, aquelas que possuíssem mais de $75 \%$ de cana própria deveriam transferir o excedente para os fornecedores.

Apesar dos decretos posteriores à instituição do Estatuto, que deveriam garantir a participação dos fornecedores no fornecimento de cana, Ramos (1999) considera que as medidas flexibilizavam a expansão paulista e aumentavam a produção própria de cana-deaçúcar, pois se firmava no reconhecimento do IAA de que os fornecedores não tinham capacidade suficiente de produção.

A sustentação pelo IAA do impedimento da expropriação dos fornecedores, mantendo a separação da atividade agrícola da industrial, dão a dimensão do seu papel institucional na definição da estrutura agrícola e industrial e de como essas medidas podem ter definido as decisões sobre a cultura própria da cana-de-açúcar ou a compra de terceiros.

Ramos (1999) afirma que os percentuais de cana própria e cana de terceiros apresentados pelas estatísticas do IAA eram subestimados, já que o IAA considerava cana de terceiros a produção advinda de arrendamento que, na realidade, poderia vir de produção das usinas em terras arrendadas.

A profunda mudança no ambiente institucional ocorrida ao final da década de 1980 e início da década seguinte alteram completamente esse controle exercido pelo IAA, que é extinto por decreto pelo presidente Fernando Collor de Melo. Paulillo et. al (2007) revelam que as mudanças no ambiente institucional do setor sucroalcooleiro tiveram impacto direto no ambiente organizacional e nas formas contratuais que passam a reger as transações de compra e venda de cana.

Com a mudança da regulamentação estatal sobre o setor, existiu um período de prevalência do livre mercado, o que gerou conflitos entre fornecedores e usinas na determinação da remuneração da tonelada. 
$\mathrm{Na}$ tentativa de minimizar esses conflitos, organizações representativas de fornecedores de cana e usinas - ORPLANA e UNICA - se uniram no intuito de apresentar regras de relacionamento entre os mesmos e viabilizar um sistema de pagamento da matéria-prima, intitulado CONSECANA (BURNQUIST, 1999).

Este modelo serviu como padrão nas contratações para fornecimento de cana por diversas unidades processadoras de cana nos estados de São Paulo e Paraná, em especial (NEVES; CONEJERO, 2010). O preço final da cana passou a ser atribuído de acordo com a qualidade, o preço médio do açúcar total recuperável (ATR) e a participação no custo da cana no custo do açúcar e álcool (CONSECANA, 2006). Este sistema permitiu, na medida da sua amplitude, reduzir os custos de transação provenientes da renegociação de contratos ou mesmo pela redução do próprio conflito.

A construção de arranjos institucionais como o CONSECANA permitiu a emergência de novos contratos e novas formas de relacionamento na cadeia sucroalcooleira. Conforme explanado por alguns autores (PEROSA; JESUS; ORTEGA, 2017; QUEIROZ, 2016; LIMA, 2010), as novas regiões produtoras de açúcar e álcool, como o Cerrado mineiro e goiano, expandiram o seu setor sucroalcooleiro a partir de novas formas contratuais e de governança.

\section{Metodologia}

O presente estudo se baseia em dados secundários, utilizando metodologias qualitativa e quantitativa. A análise qualitativa se organiza em torno de informações coletadas por meio de revisão bibliográfica, buscando trazer conceitos teóricos para fundamentar a análise, e sistematizar os estudos sobre abastecimento de cana em diferentes localidades produtoras. Apesar deste estudo não utilizar diretamente dados primários, ele usa diversos estudos que realizaram entrevistas com atores-chave nas regiões estudadas .

Já a análise quantitativa está amparada na apresentação de estatística descritiva elaborada a partir de dados coletados junto à Pesquisa Agrícola Municipal do Instituto Brasileiro de Geografia e Estatística (IBGE) e no anuário PROCANA. A partir desses dados, foram aplicadas duas medidas: a) coeficiente de variação da produtividade das mesorregiões produtoras em cada estado estudado; b) alterações percentuais da cana provinda de fornecedores e cana própria para abastecimento das usinas ao longo do tempo. Tais dados foram agregados e apresentados na forma de tabelas que ilustraram o processo de expansão do setor sucroalcooleiro e as modificações na configuração do abastecimento ao longo do tempo.

A seleção das áreas de produção ocorreu de acordo com a importância da participação dos estados e com a taxa de expansão da produção de cana-de-açúcar a partir do ano de 1990 - data mais antiga de disponibilidade dos dados agregados por mesorregiões do IBGE - apresentadas nas seções seguintes.

Assim, a escolha considerou a importância do estado na produção nacional, bem como a importância das mesorregiões dentro destes estados. Assim, foram selecionados os 
estados de São Paulo, Goiás e Minas Gerais que ocupam respectivamente a primeira, segunda e a terceira posição na produção nacional de cana, como mostra a tabela 1.

Tabela 1: Participação dos estados brasileiros na área cultivada de cana-de-açúcar $(\mathrm{em} \%)$

\begin{tabular}{c|c|c}
\hline Estado & 1990 & 2015 \\
\hline São Paulo & $41,9 \%$ & $56,4 \%$ \\
Goiás & $2,5 \%$ & $9,6 \%$ \\
Minas Gerais & $7,0 \%$ & $9,2 \%$ \\
Mato Grosso do Sul & $1,6 \%$ & $6,3 \%$ \\
Paraná & $3,7 \%$ & $5,9 \%$ \\
Alagoas & $13,0 \%$ & $2,8 \%$ \\
Mato Grosso & $1,5 \%$ & $2,7 \%$ \\
Pernambuco & $11,0 \%$ & $2,1 \%$ \\
Demais estados & $17,9 \%$ & $5,0 \%$ \\
\hline
\end{tabular}

Fonte: Elaboração dos autores a partir dos dados do PAM/IBGE (2018)

Até os anos 1990, o estado de São Paulo disputava alguma relevância com a região Nordeste. Essa situação foi se alterando ao longo de tempo com a desregulamentação do setor, abrindo espaço para a construção de novas usinas sem a imposição da sua localização ou quantidade produzida. Nos anos mais recentes, estados que possuíam menor participação na produção nacional de cana, ganharam maior espaço na produção nacional, como Goiás e Minas Gerais.

Ao se observar a evolução da produção, verifica-se que a expansão em Goiás foi bem superior à de Minas Gerais (em 1990, Goiás era responsável por apenas 2,5\% da produção nacional, enquanto Minas Gerais já era responsável por 7\%). Essa inserção mais recente de Goiás teve impactos importantes na forma de organização dessa cadeia produtiva, como poderá se verificar ao longo deste estudo.

No estado de Minas Gerais, as mesorregiões do Noroeste de Minas e Triângulo Mineiro e Alto Paranaíba (TMAP), com vegetação típica de Cerrado, representavam, em 2015, 75\% da área produzida de cana-de-açúcar no estado. Já, no estado de Goiás, onde o Cerrado é vegetação característica do total do território (original), a mesorregião do Sul Goiano, representava $80 \%$ da área plantada de cana-de-açúcar no estado, em 2015, de acordo com o IBGE (2018). 


\section{Discussão dos resultados}

\subsection{Expansão e transformações no setor sucroalcooleiro nos anos 2000}

Após o período de desregulamentação, a produção de açúcar e álcool se expandiu para outros estados brasileiros como mostrou a tabela 1. Essa expansão provocou o crescimento da produção de cana-de-açúcar em regiões anteriormente especializadas em outras atividades, como a pecuária e a produção de grãos.

Dentre as explicações para esse processo, pode-se mencionar as mudanças no ambiente institucional e as novas tecnologias que impulsionaram o consumo, como os motores flex-fuel (PEROSA, 2012). Com a desregulamentação do setor e o aumento da demanda por etanol nos anos 2000, observou-se uma maior dispersão geográfica da produção, com o surgimento de outras áreas produtoras. Outro elemento relevante nesse processo se refere às novas variedades de cana desenvolvidas para regiões mais secas, como o Cerrado (CARVALHO; FURTADO, 2013)

Esse processo de expansão aconteceu de maneira distinta entre os estados analisados. No estado de São Paulo e em Minas Gerais houve uma modificação ao longo do tempo das principais regiões canavieiras, enquanto em Goiás ocorreu apenas alteração da participação das mesorregiões, como mostram as tabelas 2,3 e 4 .

Tabela 2: Participação das mesorregiões paulistas (1990 e 2015)

\begin{tabular}{l|c|c}
\hline Mesorregião & $\mathbf{1 9 9 0}$ & $\mathbf{2 0 1 5}$ \\
\hline Ribeirão Preto (SP) & $28 \%$ & $24,5 \%$ \\
São José do Rio Preto (SP) & $8 \%$ & $18,3 \%$ \\
Bauru (SP) & $16 \%$ & $11,4 \%$ \\
Presidente Prudente (SP) & $4 \%$ & $9,9 \%$ \\
Araçatuba (SP) & $5 \%$ & $8,9 \%$ \\
Araraquara (SP) & $8 \%$ & $7,0 \%$ \\
Assis (SP) & $8 \%$ & $6,8 \%$ \\
Piracicaba (SP) & $13 \%$ & $5,5 \%$ \\
Campinas (SP) & $8 \%$ & $4,5 \%$ \\
Marília (SP) & $1 \%$ & $1,6 \%$ \\
Itapetininga (SP) & $2 \%$ & $1,2 \%$ \\
Macro Metropolitana Paulista (SP) & $1 \%$ & $0,4 \%$ \\
Vale do Paraíba Paulista (SP) & $0 \%$ & $0,0 \%$ \\
Litoral Sul Paulista (SP) & - & $0,0 \%$ \\
Metropolitana de São Paulo (SP) & $0 \%$ & $0,0 \%$ \\
\hline
\end{tabular}

Fonte: Elaboração dos autores a partir dos dados do IBGE (2018). 
Tabela 3: Participação das mesorregiões mineiras (1990 e 2015)

\begin{tabular}{l|c|c}
\hline Mesorregião & $\mathbf{1 9 9 0}$ & $\mathbf{2 0 1 5}$ \\
\hline Triângulo Mineiro/Alto Paranaíba (MG) & $34,20 \%$ & $68,9 \%$ \\
Noroeste de Minas (MG) & $1,77 \%$ & $6,2 \%$ \\
Sul/Sudoeste de Minas (MG) & $17,95 \%$ & $5,5 \%$ \\
Central Mineira (MG) & $7,09 \%$ & $4,9 \%$ \\
Norte de Minas (MG) & $8,72 \%$ & $4,1 \%$ \\
Oeste de Minas (MG) & $1,97 \%$ & $3,4 \%$ \\
Zona da Mata (MG) & $13,05 \%$ & $2,1 \%$ \\
Vale do Rio Doce (MG) & $4,16 \%$ & $1,6 \%$ \\
Metropolitana de Belo Horizonte (MG) & $3,67 \%$ & $1,2 \%$ \\
Vale do Mucuri (MG) & $2,11 \%$ & $1,0 \%$ \\
Jequitinhonha (MG) & $4,33 \%$ & $0,9 \%$ \\
Campo das Vertentes (MG) & $0,34 \%$ & $0,2 \%$ \\
\hline
\end{tabular}

Fonte: Elaboração dos autores a partir dos dados do IBGE (2018).

Em São Paulo, a mesorregião de São José do Rio Preto, assim como outras do Oeste paulista passaram a concentrar a maior parte da área plantada de cana, enquanto as chamadas áreas tradicionais, Campinas e Piracicaba, perderam participação. Em Minas Gerais e Goiás, o Triângulo Mineiro e o Sul Goiano ganharam representatividade significativa em relação à demais mesorregiões, concentrando aproximadamente $70 \%$ da área plantada em cada um desses estados no ano de 2015.

Tabela 4: Participação das mesorregiões goianas (1990 e 2015)

\begin{tabular}{l|c|c}
\hline Mesorregião & $\mathbf{1 9 9 0}$ & $\mathbf{2 0 1 5}$ \\
\hline Sul Goiano (GO) & $56,48 \%$ & $79,0 \%$ \\
Centro Goiano (GO) & $33,05 \%$ & $15,3 \%$ \\
Leste Goiano (GO) & $8,09 \%$ & $4,3 \%$ \\
Norte Goiano (GO) & $1,96 \%$ & $1,0 \%$ \\
Noroeste Goiano (GO) & $0,42 \%$ & $0,5 \%$ \\
\hline
\end{tabular}

Fonte: Elaboração dos autores a partir dos dados do IBGE (2018).

A produção canavieira do estado de Goiás está concentrada na mesorregião do Sul Goiano. Uma característica evidente ao se analisarem os dados é a elevada concentração geográfica, sendo que o Sul Goiano representava, em 2015, 79\% da produção do estado. 
Dentre os municípios que se destacam nessa região pode-se mencionar Quirinópolis, Goiatuba e Rio Verde (QUEIROZ, 2016).

Já, no estado de Minas Gerais, observa-se uma concentração da produção em apenas uma mesorregião, a do TMAP. Apesar da produção de cana no TMAP ter se iniciado nos anos 1980, é a partir dos anos 2000 que acontece a sua grande expansão (PEROSA; JESUS; ORTEGA, 2017).

Para identificar as mesorregiões de maior e menor expansão calculamos a taxa de crescimento da área plantada de cana-de-açúcar nos estados de São Paulo, Minas Gerais e Goiás, conforme as tabelas 5, 6 e 7. As taxas de expansão da área foram calculadas para os períodos de 1990-1999 e 2000-2015.

\begin{tabular}{|c|c|c|}
\hline Mesorregiões & $1990 / 1999$ & $2000 / 2015$ \\
\hline Marília (SP) & $-65,0 \%$ & $2002 \%$ \\
\hline Presidente Prudente (SP) & $31,4 \%$ & $534 \%$ \\
\hline São José do Rio Preto (SP) & $55,5 \%$ & $351 \%$ \\
\hline Araçatuba (SP) & $66,6 \%$ & $217 \%$ \\
\hline Itapetininga (SP) & $-11,0 \%$ & $122 \%$ \\
\hline Bauru (SP) & $20,5 \%$ & $104 \%$ \\
\hline Assis (SP) & $42,9 \%$ & $100 \%$ \\
\hline Araraquara (SP) & $65,7 \%$ & $69 \%$ \\
\hline Ribeirão Preto (SP) & $64,2 \%$ & $64 \%$ \\
\hline Campinas (SP) & $33,8 \%$ & $59 \%$ \\
\hline Piracicaba (SP) & $3,9 \%$ & $28 \%$ \\
\hline Total SP & $41,0 \%$ & $124 \%$ \\
\hline
\end{tabular}

Fonte: Elaboração dos autores a partir dos dados do IBGE (2018).

Nota: As mesorregiões Vale do Paraíba Paulista, Litoral Sul Paulista, Metropolitana de São Paulo e Macro Metropolitana Paulista foram excluídas desta tabela, já que possuem uma participação irrisória na área produzida em relação às demais e apresentam indisponibilidade de dados para alguns anos, inviabilizando o cálculo da taxa de expansão.

Os dados do IBGE revelam que na região do Cerrado brasileiro (TMAP, Noroeste e Oeste de Minas e estado de Goiás), a atividade canavieira se expandiu intensamente no período considerado (1990-2015). Essa expansão ocorreu pela ocupação de pastagens degradados e áreas antes utilizadas para outras atividades agrícolas (especialmente grãos e pecuária de baixa produtividade). Enquanto isso, no estado de São Paulo, as terras foram ocupadas com a atividade agropecuária desde o período colonial, restando poucas terras para uma nova expansão agrícola. 
Tabela 6: Expansão da área plantada com cana nas mesorregiões mineiras (em \%)

\begin{tabular}{l|c|c}
\hline Mesorregiões & $\mathbf{1 9 9 0 / 1 9 9 9}$ & $\mathbf{2 0 0 0 / 2 0 1 5}$ \\
\hline Triângulo Mineiro/Alto Paranaíba (MG) & $6,6 \%$ & $400 \%$ \\
Oeste de Minas (MG) & $22,3 \%$ & $377 \%$ \\
Vale do Mucuri (MG) & $-15,7 \%$ & $105 \%$ \\
Norte de Minas (MG) & $20,9 \%$ & $70 \%$ \\
Central Mineira (MG) & $-36,4 \%$ & $68 \%$ \\
Sul/Sudoeste de Minas (MG) & $7,3 \%$ & $48 \%$ \\
Vale do Rio Doce (MG) & $-28,4 \%$ & $9 \%$ \\
Jequitinhonha (MG) & $139,4 \%$ & $2 \%$ \\
Campo das Vertentes (MG) & $-18,6 \%$ & $-14 \%$ \\
Metropolitana de Belo Horizonte (MG) & $14,8 \%$ & $-19 \%$ \\
Zona da Mata (MG) & $-24,9 \%$ & $-34 \%$ \\
Total MG & $\mathbf{- 7 , 0 \%}$ & $\mathbf{2 1 4 \%}$ \\
\hline
\end{tabular}

Fonte: Elaboração dos autores a partir dos dados do IBGE (2018)

Koga-Vicente, Zullo Júnior e Aidar (2013) apontam que essa movimentação levanta questionamentos sobre a ocupação da terra, podendo trazer impactos sobre a segurança alimentar e a preservação ambiental nessas regiões. Acrescenta-se o fato de que a expansão da cana-de-açúcar no estado de São Paulo, dada a restrição de terras, elevou consideravelmente a preço da terra. A terra "nua" no Estado de São Paulo apresentou um aumento do preço médio de $15 \%$ ao ano, por hectare, entre 2000 e 2015 (SÃO PAULO/IEA, 2018)

Tabela 7: Expansão da área plantada com cana nas mesorregiões goianas (em \%)

\begin{tabular}{l|c|c}
\hline Mesorregiões & $\mathbf{1 9 9 0 / 1 9 9 9}$ & $\mathbf{2 0 0 0 / 2 0 1 5}$ \\
\hline Noroeste Goiano (GO) & $-21,8 \%$ & $978 \%$ \\
Sul Goiano (GO) & $56,0 \%$ & $743 \%$ \\
Leste Goiano (GO) & $-9,7 \%$ & $442 \%$ \\
Norte Goiano (GO) & $-6,4 \%$ & $417 \%$ \\
Centro Goiano (GO) & $24,4 \%$ & $235 \%$ \\
Total GO & $\mathbf{3 9 , 1 \%}$ & $\mathbf{5 6 8 \%}$ \\
\hline
\end{tabular}

Fonte: Elaboração dos autores a partir dos dados do IBGE (2018).

Nota: O Noroeste Goiano, apesar de uma elevada expansão da área de produção entre os anos de 2000 e 2015, possui também uma participação relativamente pequena na área de produção, como mostrado na tabela 2. 
A expansão da cana-de-açúcar no Cerrado começou efetivamente nos anos 2000. Isso pode ser explicado como uma resposta à crescente demanda por biocombustíveis, gerada tanto pela demanda doméstica inflada pela introdução dos motores flex fuel, quanto pelas expectativas de expansão do mercado internacional devido a acordos ambientais e a crescente demanda por combustíveis mais sustentáveis (PEROSA, 2012).

Para suprir essa demanda crescente, ocorreu aumento na produção canavieira em regiões tradicionais do estado de São Paulo e também em novas regiões produtoras, seja no estado de São Paulo ou em outras unidades da Federação. Em São Paulo, a expansão da produção de cana caminhou em direção a regiões tradicionalmente voltadas a pecuária, como Araçatuba e Presidente Prudente. Em outros estados, também ocorreu a expansão dos canaviais, a saber: em Minas Gerais, Goiás, Mato Grosso e Mato Grosso do Sul.

Apesar da expansão da produção canavieira para regiões não tradicionais no estado de São Paulo, a produtividade observada nas mesorregiões paulistas não é tão diferente quanto nas mesorregiões mineiras e goianas, como mostra a tabela 8.

Tabela 8: Medidas de variação para o rendimento médio das mesorregiões paulistas, mineiras e goianas

\begin{tabular}{c|cc|cc|cc}
\hline \multirow{2}{*}{ Medidas estatísticas } & \multicolumn{2}{|c|}{ São Paulo } & \multicolumn{2}{c|}{ Minas Gerais } & \multicolumn{2}{c}{ Goiás } \\
\cline { 2 - 7 } & $\mathbf{2 0 0 0}$ & $\mathbf{2 0 1 5}$ & $\mathbf{2 0 0 0}$ & $\mathbf{2 0 1 5}$ & $\mathbf{2 0 0 0}$ & $\mathbf{2 0 1 5}$ \\
\hline Rendimento Médio & 76.011 & 76.632 & 50.459 & 64.803 & 52.385 & 70.203 \\
Desvio padrão & 4.766 & 4.385 & 15.914 & 11.867 & 24.838 & 11.068 \\
Coeficiente de Variação & $6 \%$ & $6 \%$ & $32 \%$ & $18 \%$ & $47 \%$ & $16 \%$ \\
\hline
\end{tabular}

Fonte: Elaboração dos autores a partir dos dados do IBGE (2018)

A produtividade no estado de São Paulo não sofreu alterações significativas nos 15 anos estudados, assim como a diferença de produtividade entre as mesorregiões também não se alterou - fato observado na linha do coeficiente de variação1. Os estados de Minas Gerais e Goiás apresentaram uma melhora significativa no rendimento médio da área produzida e também uma redução nas diferenças de produtividade das mesorregiões produtoras de cana.

Até a década de 1970, as terras do Cerrado (latossolos) eram consideradas impróprias para o cultivo agrícola. Porém, a evolução da pesquisa científica sobre o uso adequado de corretivos de acidez e de fertilizantes, manejo do solo, rotação de culturas somadas às condições edafoclimáticas 2 permitiram a expansão da agricultura nesse bioma e a consequente melhoria da produtividade da terra nessas áreas (FRANCISCO; KAPPES, 2012). Esses aperfeiçoamentos nos tratos culturais e no uso do solo no Cerrado reduziram

\footnotetext{
${ }^{1} \mathrm{O}$ coeficiente de variação, na última linha da tabela 8 , mostra o quanto a produtividade das mesorregiões dos estados se afasta da própria produtividade média.

${ }^{2}$ Características definidas através de fatores do meio tais como o clima, o relevo, a temperatura, a humidade do ar, a radiação, o tipo de solo, o vento, a composição atmosférica e a precipitação pluvial.
} 
as discrepâncias de produtividade da cana-de-açúcar nas mesorregiões de Goiás e Minas Gerais.

As diferenças de produtividade que existiam nas mesorregiões do Cerrado afetaram o interesse dos proprietários de usinas em integrar ou não a produção de cana-de-açúcar, já que ela é responsável por uma parcela significativa dos custos de produção industriais cerca de $60 \%$.

Um outro fator relevante na decisão da usina em integrar ou não a produção industrial e agrícola é o tamanho médio das usinas. A tabela 9 mostra o tamanho das usinas pesquisadas no Anuário da Cana (PROCANA, 2001/2002; 2015).

\section{Tabela 9: Tamanho médio das usinas em São Paulo, Minas Gerais e Goiás (em toneladas moídas)}

\begin{tabular}{c|c|c}
\hline Estado & $\mathbf{2 0 0 1}$ & $\mathbf{2 0 1 5}$ \\
\hline Minas Gerais & $598.375,74$ & $2.543 .164,88$ \\
Goiás & $804.078,36$ & $2.157 .338,64$ \\
São Paulo & $1.515 .727,65$ & $2.830 .548,85$ \\
\hline
\end{tabular}

Fonte: Elaboração dos autores a partir dos dados do PROCANA (2001/2002; 2015)

Nos três estados considerados, o tamanho médio das usinas aumentou, o que significa que novas usinas surgiram (independentes ou pertencentes a grupos) com capacidade de processamento de cana maior do que no ano de 2001. Esse aumento na escala das usinas também representa maior necessidade de planejamento da capacidade produtiva e, por conseguinte, maior necessidade de controle no abastecimento de cana-de-açúcar. Em muitas regiões, esse planejamento não ocorreu, como em regiões tradicionais do estado de São Paulo (a exemplo de Ribeirão Preto), em que a capacidade instalada era muito superior à cana disponível na distância viável de transporte (BELIK et al, 2017). Como consequência, observou-se elevada capacidade ociosa, com aumento nos custos e piora na eficiência das usinas.

A seguir discutiremos os elementos que marcaram essa nova fase de expansão do setor sucroalcooleiro no período recente, com especial ênfase nas estruturas de governança utilizadas na transação de abastecimento de cana pelas usinas.

\subsubsection{Expansão e governança no setor sucroalcooleiro paulista}

A expansão no estado de São Paulo para regiões consideradas como não tradicionais ocorreu a partir do PROÁLCOOL. Esse impulso foi sentido também em outros estados brasileiros, e na região Oeste do estado de São Paulo, que aliado aos incentivos governamentais para a instalação de novas usinas e, mais tarde, nos anos 2000, com o advento do motor flex fuel e o aumento da demanda por etanol, levou a expansão da produção de cana-de-açúcar aos estados de Goiás e Minas Gerais. 
Até então, como mostramos na tabela 1 deste artigo, a produção se concentrava na região Nordeste e no estado de São Paulo, em especial na região Leste e Central paulista, ou seja, nas chamadas regiões tradicionais como Ribeirão Preto, Bauru e Piracicaba.

No que tange as estruturas de governança utilizadas, observa-se que em São Paulo a cana-de-açúcar era produzida tanto por fornecedores quanto pela própria usina, como apontou a literatura como mostram os dados do PROCANA (2001; 2002), na tabela 10.

\section{Tabela 10: Distribuição do abastecimento de cana nas usinas paulistas nas safras 2001/2002 e 2015}

\begin{tabular}{c|c|c|c|c}
\hline Forma de abastecimento & $\mathbf{2 0 0 1 / 2 0 0 2}(\mathbf{e m}$ ton) & $\mathbf{\%}$ & $\mathbf{2 0 1 5}(\mathbf{e m ~ t o n})$ & \% \\
\hline Própria & 65.923 .193 & $48,9 \%$ & 152.050 .620 & $88,5 \%$ \\
Fornecedores & 37.553 .495 & $27,8 \%$ & 16.907 .707 & $9,8 \%$ \\
Acionistas & 31.423 .073 & $23,3 \%$ & 2.904 .627 & $1,7 \%$ \\
Total & 134.899 .761 & - & 171.862 .954 & - \\
\hline
\end{tabular}

Fonte: Elaboração dos autores a partir dos dados do PROCANA (2001/2002; 2015)

Notas metodológicas:

1. De um total de 125 usinas listadas no Anuário do PROCANA em 2001/2002, 88 discriminaram a forma de abastecimento de cana-de-açúcar

2. De um total de 171 usinas listadas no Anuário do PROCANA em 2015, 42 discriminaram a forma de abastecimento de cana-de-açúcar

Até o período da desregulamentação do setor, existia uma maior participação da cana de fornecedores, como aponta a tabela 6. Os dados levantados por Feltre (2014) também indicavam que até a desregulamentação havia uma participação sensivelmente maior de cana de fornecedores no Brasil.

As denominações e terminologias para descrever as estruturas de governança no abastecimento de cana encontradas na literatura são bastante variadas - existe uma série delas entre mercado spot e integração vertical. É relativamente comum em áreas de expansão de cana-de-açúcar o contrato de parceria, regulamentado em 1966 (BRASIL, 1966), e que se aproxima bastante da integração vertical.

Nesta forma de abastecimento a usina acerta com o proprietário da terra que ela será responsável por plantar, renovar, cultivar e colher a cana-de-açúcar3, sendo responsável por todas as despesas desta etapa. Ao proprietário da terra será designado um percentual da cana colhida em forma de remuneração por ter cedido a terra para a produção.

A movimentação das usinas paulistas em direção à estrutura intitulada "cana própria" contempla as parcerias, pois nesta se entende que a cana, tanto aquela que se torna

\footnotetext{
${ }^{3}$ Alguns contratos especificam as atividades que serão desenvolvidas pelas usinas como aplicar a mão-de-obra e o maquinário, efetuar todos os serviços correspondentes a destoca, aração, sulcação, adubação, plantio, tratos culturais, aplicação de fertilizantes, herbicidas, fungicidas, corte, carregamento e transporte da cana-de-açúcar.
} 
remuneração do proprietário da terra, quanto aquela que é destinada à própria usina, é de produção das usinas, entretanto em terras de terceiros (FELTRE, 2014).

Antes do processo de desregulamentação eram comuns três denominações no fornecimento de cana: i) a integração vertical total, na qual as usinas plantam cana em terras próprias; ii) o arrendamento, no qual as usinas plantam cana em terras de terceiros por meio do pagamento de toneladas/área plantada e são responsáveis por aquelas mesmas atividades da parceria - contemplam a chamada cana própria - e, iii) a cana que era recebida de fornecedores de cana independentes a preços estabelecidos pelo IAA.

Ao que tudo indica, as diferenças entre contratos de arrendamento e de parceria residem no fato de que, na primeira, existe maior segurança por parte do arrendante que recebe uma quantidade pré-estabelecida equivalente a toneladas de cana/hectare, enquanto que na parceria o proprietário da terra recebe um percentual da cana colhida por hectare. Como mostram Almeida e Buainain (2013), "na parceria [...] os rendimentos e a produção obtidos são, ao final do contrato, partilhados; bem como os riscos do empreendimento, na proporção acordada, e em conformidade aos limites impostos pela lei”.

Amaral (2009) aponta que nesta modalidade o parceiro não sai do negócio da cana, pois continua recebendo um volume anual de cana e seu nome continua relacionado na associação de fornecedores de cana a qual pertence. Porém, vale considerar que, neste tipo de estrutura de governança, o parceiro que antes era produtor de cana, acaba se desfazendo dos bens de capital que possuía antes de entrar neste modelo de negócio, o que reduz seu poder de barganha na renegociação dos contratos.

As áreas de produção de cana-de-açúcar no estado de São Paulo são bastante heterogêneas quanto a expansão ao longo do tempo, condições de declividade do solo, culturas agrícolas tradicionais, entre outros. No entanto, estudos sobre as estruturas de governança mostram que as usinas tanto em áreas de expansão como áreas tradicionais optam por estruturas similares, diferenciando-se em suas proporções.

Amaral (2009) também mapeou algumas estruturas de governança no abastecimento de cana e encontrou, entre as já citadas anteriormente, outros formatos híbridos nas transações de abastecimento de cana. Entre esses formatos, o autor cita as parcerias majoritárias, que se assemelham à parceria citada anteriormente, e minoritárias, na qual a usina cede terras sob sua responsabilidade (sejam próprias ou arrendadas) para produtores agrícolas produzirem cana e ficam com um percentual minoritário da produção.

A região de São José do Rio Preto, Marília, Presidente Prudente, e Araçatuba são consideradas como áreas de expansão da produção de cana-de-açúcar. Nestas regiões, a mecanização da lavoura é predominante em relação ao trabalho manual, dada as condições de declividade menor do solo.

De acordo com Dedecca (2009), a atividade econômica e a urbanização dessas regiões foram impulsionadas pelo café. Ao longo do tempo outras atividades agrícolas e pecuárias ganharam espaço na região como a pecuária bovina, a cana-de-açúcar, a laranja e o milho. Já, na década de 1940, a atividade agrícola encontrava-se mais diversificada. Na atividade industrial ganharam espaço na economia dessas regiões a indústria de móveis, confecções e alimentos (DEDECCA, 2009). 
Em estudo nessas áreas de expansão, Feltre (2014) procurou mostrar as estruturas de governança que estavam presentes no abastecimento de cana. Os resultados não foram diferentes dos observados em Ribeirão Preto, ou seja, nessa região existem também uma variedade de estruturas de governança nas usinas similares às encontradas por Amaral (2009). Entretanto, acrescenta-se a esta discussão o fato de aparecerem nas áreas de expansão algumas transações próximas ao mercado spot, contudo com algum nível de compromisso entre as partes como período da entrega da cana e forma de pagamento, o que a autora denominou de "contrato relacional".

O mercado spot não é uma estrutura de governança muito comum nas áreas de expansão, já que a concorrência pela cana é intensa e os proprietários das usinas precisam ter garantido o abastecimento da unidade industrial no longo prazo, assim como os produtores de cana-de-açúcar precisam garantir a venda do produto à usina.

A produtividade na etapa agrícola é considerada crucial pelas usinas na determinação da rentabilidade das mesmas, pois a cana-de-açúcar é responsável por $60 \%$ dos custos industriais, o que exige dos produtores conhecimento sobre as técnicas de plantio e tratos culturais (FELTRE; PAULILLO; SOUZA FILHO, 2014).

Com a expansão da cana-de-açúcar em áreas com atividades da agricultura e pecuária variadas, houve certa dificuldade por parte das usinas em encontrar produtores rurais com habilidades na cultura de cana-de-açúcar. Tal dificuldade conduziria as usinas paulistas, em áreas de expansão, a optarem pela modalidade de parceria.

É possível que, em regiões nas quais os produtores de cana-de-açúcar sejam mais capitalizados e/ou possuam outras fontes de renda, as transações via mercado spot possam ocorrer com mais frequência.

\subsubsection{Expansão e governança no setor sucroalcooleiro no Cerrado}

Como mencionado anteriormente, a nova expansão da cana-de-açúcar ocorreu em regiões que eram dominadas por outras atividades agrícolas, como a pecuária e a produção de grãos. Logo, nessas novas áreas não existia uma rede de produtores de cana-de-açúcar para atender às usinas. Assim, na maior parte dos casos, as usinas foram as responsáveis pela produção de cana ou por engajar outros agricultores a produzir cana de açúcar para suprir sua demanda local.

Dessa forma, várias usinas tiveram de comprar ou arrendar terras por conta própria de forma a produzir o mínimo de matéria-prima necessária para operar suas novas instalações. Vale lembrar que as usinas modernas apresentam uma vantagem de custo considerável ao moerem mais de 2 milhões de toneladas ao ano (BELIK et al., 2017).

Na safra de 2001/2002, o anuário do PROCANA (2001/2002) mostrou que o número de usinas tanto no estado de Minas Gerais quanto em Goiás era relativamente reduzido. Nos dois estados em questão a forma de abastecimento predominante era a cana própria, como mostram as tabelas 10 (usinas goianas) e 11 (usinas mineiras). 
Tabela 10: Distribuição do abastecimento de cana nas usinas goianas nas safras 2001/2002 e 2015

\begin{tabular}{c|c|c|c|c}
\hline Forma de abastecimento & $\mathbf{2 0 0 1 / 2 0 0 2}(\mathbf{e m}$ ton) & $\boldsymbol{\%}$ & $\mathbf{2 0 1 5}(\mathbf{e m}$ ton) & $\boldsymbol{\%}$ \\
\hline Própria & 7.690 .373 & $86,9 \%$ & 35.256 .255 & $96 \%$ \\
Fornecedores & 51.217 & $0,6 \%$ & 1.418 .502 & $4 \%$ \\
Acionistas & 1.103 .272 & $12,5 \%$ & - & $0 \%$ \\
Total & 8.844 .862 & & 36.674 .757 & \\
\hline
\end{tabular}

Fonte: Elaboração dos autores a partir dos dados do PROCANA (2001/2002; 2015)

Notas metodológicas:

1. De um total de 11 usinas listadas no Anuário do PROCANA em 2001/2002, 11 discriminaram a forma de abastecimento de cana-de-açúcar

2. De um total de 40 usinas listadas no Anuário do PROCANA em 2015, 17 discriminaram a forma de abastecimento de cana-de-açúcar

Esse predomínio da cana própria é explicado pela falta de uma rede de fornecedores nessas novas áreas, o que teria incentivado as usinas a gerir uma maior proporção de sua matéria-prima, com o propósito de garantir um abastecimento estratégico.

Tabela 11: Distribuição do abastecimento de cana nas usinas mineiras nas safras 2001/2002 e 2015

\begin{tabular}{c|c|c|c|c}
\hline Forma de abastecimento & $\mathbf{2 0 0 1 / 2 0 0 2}(\mathbf{e m}$ ton) & $\mathbf{\%}$ & $\mathbf{2 0 1 5}(\mathbf{e m ~ t o n})$ & \% \\
\hline Própria & 8.194 .262 & $72,1 \%$ & 11.562 .147 & $37,9 \%$ \\
Fornecedores & 2.729 .844 & $24,0 \%$ & 11.567 .053 & $37,9 \%$ \\
Acionistas & 445.033 & $3,9 \%$ & 7.388 .779 & $24,2 \%$ \\
Total & 11.369 .139 & & 30.517 .979 & \\
\hline
\end{tabular}

Fonte: Elaboração dos autores a partir dos dados do PROCANA (2001/2002; 2015)

Notas metodológicas:

1. De um total de 20 usinas listadas no Anuário do PROCANA em 2001/2002, 19 discriminaram a forma de abastecimento de cana-de-açúcar

2. De um total de 42 usinas listadas no Anuário do PROCANA em 2015, 12 discriminaram a forma de abastecimento de cana-de-açúcar

Contudo, os dados do Anuário PROCANA revelam que, em períodos mais recentes, apesar da forma dominante de abastecimento via cana própria ter se mantido em Goiás, aconteceu uma modificação significativa em Minas Gerais, com mais fornecedores dividindo o abastecimento total de cana-de-açúcar na usina, situação visualizada no Gráfico 1 . 


\section{Gráfico 1. Distribuição de cana nos estados de Goiás e Minas Gerais (2001/2002 e 2015)}

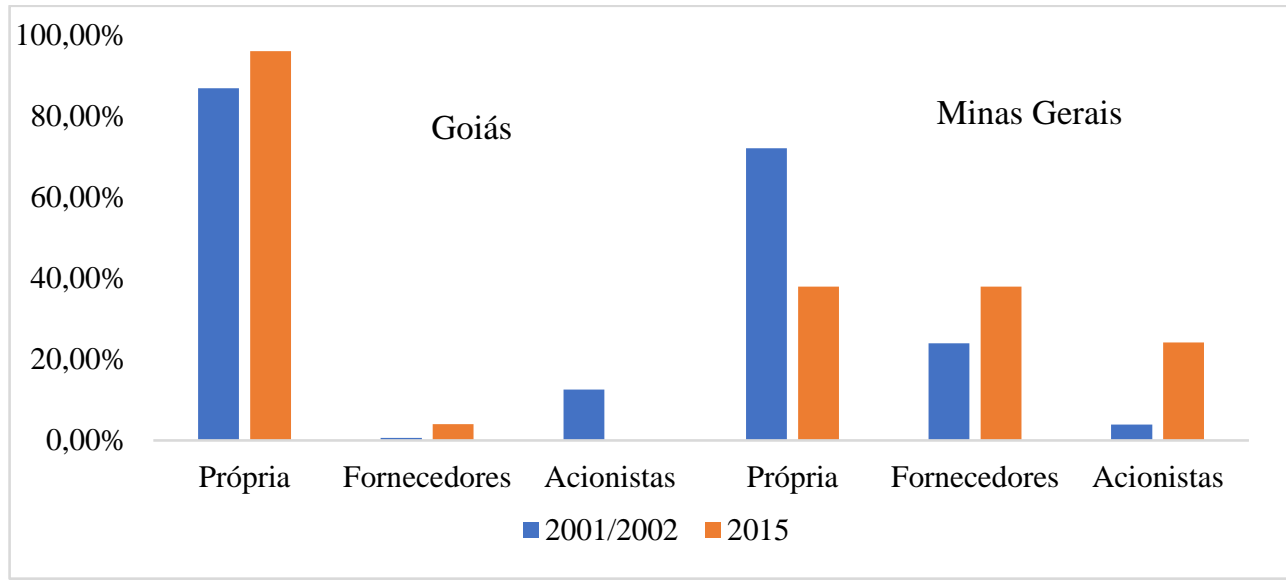

Fonte: Elaboração dos autores a partir dos dados do PROCANA (2001/2002; 2015)

Para compreender melhor os números apresentados nas tabelas 7 e 8 e as diferenças mostradas na figura 1, é interessante analisar a forma como o setor sucroalcooleiro se estabeleceu nesses dois estados.

Dado que não havia produtores de cana, as usinas pioneiras que se estabeleceram no Cerrado precisaram convencer agricultores a converter o uso de suas terras. Segundo Perosa, Jesus e Ortega (2017), para convencer os agricultores a ingressar na atividade, usinas contaram com dificuldades financeiras de produtores de grãos e passaram a oferecer uma série de vantagens. Em 2002, os preços da soja e do milho estavam em patamares baixos, além de quebras de safra, levando assim parte considerável desses produtores de grãos a dificuldades financeiras. Alguns tinham dificuldades em buscar financiamentos bancários, dada a dificuldade de saldar dívidas passadas. Nesse sentido, usinas se ofereceram para dar garantias aos empréstimos de produtores que iniciassem a produção de cana-de-açúcar. Esse processo ocorreu em diversas regiões do Cerrado, como TMAP e Sudoeste Goiano.

Dada a forma diferenciada que se estabeleceram as relações de fornecimento de cana no Cerrado, observaram-se uma série de novos arranjos de coordenação para governar essas transações. Formas contratuais híbridas, situadas entre o mercado spot e a integração vertical (cana própria) vem se desenvolvendo com essa finalidade. Uma das características desses novos contratos está na terceirização de algumas atividades ligadas ao fornecimento como, por exemplo, o corte, o carregamento e o transporte (CCT) da cana-de-açúcar.

Vale ressaltar que as formas contratuais escolhidas também são resultado do processo de mecanização que marca a expansão da cana-de-açúcar nas regiões de Cerrado. Por se tratar de áreas planas, e que iniciaram sua expansão com um padrão tecnológico já estabelecido, as regiões canavieiras no Cerrado apresentam índices de mecanização acima de $98 \%$. Tal situação também é comum nas áreas de expansão paulistas, como Araçatuba 
e Presidente Prudente (BELIK et al., 2017). Essa configuração impacta diretamente sobre as formas das transações de compra e venda de cana que são realizadas.

Também é interessante ressaltar o perfil dos agricultores que entraram na cultura canavieira. Geralmente, são produtores de médio e grande porte que atuavam no setor de grãos, o que lhes confere um grau de capitalização e de independência produtiva superior aos observados no setor canavieiro mais tradicional.

No caso de Goiás, apesar dos dados do anuário PROCANA apresentarem uma continuidade da elevada proporção da cana própria4, estudos recentes vêm apontando mudanças nesse padrão. Queiroz (2016) e Lima (2010) relatam que, apesar da primeira fase da expansão da cana no Cerrado ter ocorrido primordialmente ao partir do modelo mais integrado na usina, recentemente, observa-se um processo de separação. Essa mudança no modelo de governança estaria ocorrendo pela maior organização dos produtores em associações que buscam gerir a produção e a comercialização com as usinas.

Estes autores ressaltam que isso ocorreu especialmente em regiões com a presença de grandes produtores, egressos da produção de grãos. Estes grandes produtores não se adaptaram ao modelo de governança com um maior controle por parte da usina, como a gestão das operações de corte, carregamento e transporte (CCT). Queiroz (2016) e Lima (2010) denominam esse comportamento menos integrado como "novo" modelo, em detrimento ao sistema "tradicional", mais integrado, e que marca a primeira fase da expansão da cana em Goiás. Em muitos casos, as associações passaram a gerir inclusive as atividades de CCT, gerindo as máquinas colheitadeiras e os caminhões necessários para essas operações.

Processo semelhante foi verificado por Perosa, Jesus e Ortega (2017) na região do TMAP. No município de Campo Florido, grandes produtores de grãos se reuniram em torno de uma associação, a CANACAMPO, que foi especialmente criada para gerir a comercialização da produção junto a uma usina da região. Contudo, neste caso, a associação não é responsável pela gestão de colheitadeiras e caminhões para transporte da cana. Isso acontece por meio de consórcios entre pequenos grupos de produtores (em geral, menos de dez) que partilham seu uso e manutenção. A CANACAMPO até auxilia na gestão financeira desses consórcios, apesar de não se envolver diretamente na compra e na manutenção deles.

Assim, observa-se que apesar da produção no Cerrado ter se iniciado sob um modelo mais integrado entre produção de cana e usinas, em várias regiões, esse processo está se revertendo na direção da menor integração, como no TMAP, em Minas Gerais.

\footnotetext{
${ }^{4}$ Apesar do anuário PROCANA ser a única publicação com essas informações, vale uma ressalva quanto a sua representatividade devido ao elevado número de usinas que não discriminam sua forma de abastecimento. Em Goiás, das 40 usinas registradas em 2015, apenas 17 discriminaram sua forma de obtenção de cana, uma taxa inferior a 50\%. Em Minas Gerais, essa proporção é ainda menor com apenas 12 usinas para um total de 42. É interessante destacar que, no anuário de 2002, essa proporção era de quase $90 \%$.
} 


\section{Considerações finais}

O desenvolvimento do setor sucroalcooleiro brasileiro passou por diversas fases distintas até atingir a configuração atual, que ainda se mantém em transformação. Dentre os elementos mais marcantes desse processo estão as mudanças na participação das regiões produtoras de cana-de-açúcar na produção nacional e as alterações nas estruturas de governança utilizadas no processo de expansão da produção para áreas tradicionais no cultivo de outras culturas e na produção pecuária.

Após os anos 1990, a região Nordeste que possuía participação relativamente significativa na produção nacional, perdeu importância para outras áreas produtoras ou mesmo não tradicionais na produção de cana-de-açúcar. O estado de São Paulo ganhou ainda mais proeminência na produção nacional com a expansão da cana para regiões tradicionais na atividade pecuária. Minas Gerais que já possuía alguma participação na produção nacional também verificou expansão da produção de cana, especialmente, para áreas do Cerrado mineiro. As modificações foram mais relevantes no estado de Goiás que, até os anos 2000, possuía uma participação irrisória na produção nacional e, em 2015, passou a ocupar o segundo lugar como maior produtor de cana-de-açúcar do Brasil.

É interessante notar que o movimento de transformação nas formas de governança, do modelo "tradicional" para o "novo", é diferente do que se observa nas novas regiões produtoras de São Paulo, que também se iniciaram sob um modelo mais integrado (semelhante ao modelo tradicional do Cerrado). Isso se explica tanto pelo perfil dos grupos usineiros quanto pelo perfil dos produtores que passaram a fornecer cana nessas regiões.

No início do processo de desregulamentação nos anos 2000, grupos estrangeiros passaram a comprar ou mesmo construir unidades produtoras de açúcar e álcool no Brasil. Nessas formas de inserção, proprietários das usinas vendidas passaram a ser acionistas delas, gerindo as propriedades rurais que eram de posse das usinas. Também foi observado que, não havia habilidade suficiente por parte dos novos gestores de usinas para produzir cana-de-açúcar. Assim sendo, as usinas se desfizeram das propriedades rurais focando na produção industrial, afetando diretamente as formas de governança do abastecimento.

Do ponto de vista das usinas, observam-se diferentes perfis de gestão, das gestões mais familiares até as mais empresariais. Grupos de origem familiar tendem a buscar maior controle do processo (QUEIROZ, 2016), favorecendo relações de fornecimento por meio de cana própria ou de contratos que envolvem o CCT. Já grupos com perfil mais empresarial, geralmente vinculados a multinacionais ou grandes grupos nacionais advindos de outros setores, não se mostram tão preocupados em controlar essas etapas, adquirindo boa parte de sua matéria-prima por meio do fornecimento mais independente. A distinção destes dois perfis de grupos usineiros no Oeste paulista e no Cerrado poderia explicar as razões das relações se tornarem menos integradas nesses outros estados.

Essas constatações têm implicações para a gestão empresarial, em especial, ao poder de barganha das usinas junto aos seus fornecedores de matérias-primas. Na região do TMAP, existem instituições que, reunindo fornecedores, são responsáveis pela negociação da cana junto às usinas. Na região de Ribeirão Preto, os produtores de cana são mais 
capitalizados e a competição por cana é elevada, o que também aumenta o poder de negociação com as usinas. Já, nas áreas de expansão no estado de São Paulo, os produtores são em boa parte menores, porém, pela aptidão da terra ao cultivo da cana, existe intensa concorrência pelos fornecedores disponíveis.

Enfim, a opção das usinas pela forma de abastecimento da matéria-prima é resultado de um conjunto de fatores institucionais e de exigências de qualidade. Avançar no entendimento dos efeitos das opções sobre os resultados econômicos e financeiros das usinas se torna relevante, já que podem apontar a evolução da competitividade do setor nas diferentes regiões produtoras.

\section{Agradecimentos}

Os autores gostariam de agradecer aos editores e pareceristas da revista, pelas valiosas contribuições e minuciosa revisão do texto.

\section{Referências}

ALMEIDA, Patrícia José de; BUAINAIN, Antônio Márcio. Os contratos de arrendamento e parceria no Brasil. Revista Direito GV, [s.1.], v. 9, n. 1, p.319-343, jun. 2013. FapUNIFESP (SciELO). http://dx.doi.org/10.1590/s1808-24322013000100012.

AMARAL, R. O. Análise da transação de suprimento de cana-de-açúcar e os relacionamentos inter-organizacionais. 2009. $131 \mathrm{f}$. Dissertação (Mestrado) - Curso de Administração das Organizações, Administração, Universidade de São Paulo, Ribeirão Preto, 2009.

AOKI, M. Towards a Comparative Institutional Analysis. Cambridge: MIT press. 2001.

AZEVEDO, P. F. Nova Economia Institucional: referencial geral e aplicações para a agricultura. Agricultura em São Paulo, São Paulo, v. 47, n. 1, p. 33-52, 2000

BELIK, W. Agroindústria processadora e política econômica. 1992. 219 f. Tese (Doutorado) - Curso de Economia, Instituto de Economia, Universidade Estadual de Campinas, Campinas, 1992.

; PAUlillO, L.; VIAN, C. E. de F. A emergência dos conselhos setoriais na agroindústria brasileira: gênese de uma governança mais ampla? Rev. Econ. Sociol. Rural, Brasília , v. 50, n. 1, p. 9-32, Mar. 2012. https://doi.org/10.1590/S010320032012000100001.

.; PEROSA, B.; FIGUEIRA, S. R.; VINCENTE, A. K. Milling capacity and supply competition on sugar-ethanol industry in São Paulo, Brasil. Geografia (Rio Claro. impresso), v. 41, p. 39-56, 2017.

BRASIL. Presidência da República. Decreto-lei no 3855, de 21 de novembro de 1941. Estatuto da lavoura canavieira. Disponível em: 
<http://www.planalto.gov.br/ccivil/Decreto-Lei/Del3855.htm> Acesso em: março de 2018. Decreto $\mathrm{n}^{\circ}$ 59566, de 14 de novembro de 1966. Regulamenta as Seções I, II e III do Capítulo IV do Título III da Lei no 4.504, de 30 de novembro de 1964, Estatuto da Terra, o Capítulo III da Lei $\mathrm{n}^{\circ} 4.947$, de 6 de abril de 1966, e dá outras providências.. Decreto no 59.566, 14 de Novembro de 1966. Brasília, 17 nov. 1966. Disponível em: <http://www.planalto.gov.br/ccivil_03/decreto/antigos/d59566.htm>. Acesso em: 16 mar. 2018.

Senado Federal. Decreto n ${ }^{\circ} 76.593$, de 14 de novembro de 1975. Institui o Programa Nacional do Álcool e dá outras Providências. Disponível em:

$<$ http://www6.senado.gov.br/legislacao/ListaPublicacoes.action?id=123069 > Acesso em: agosto de 2010.

BURNQUIST, H. L. Pagamento de cana: o sistema de remuneração da tonelada de cana pela qualidade - CONSECANA. Preços agrícolas, Piracicaba, v. 14, p.14-16, 1999.

CARVALHO, S. A.; FURTADO, A. T. O Setor Sucroenergético Brasileiro: uma análise das condições varietais e seus desafios tecnológicos. Revista de Economia Agrícola (Impresso), v. 60, p. 77-90, 2013.

CONEJERO, M. A.; SIA, E. J.; PINTO, M. J. A.; IGUCHI, R. K. S.; AMARAL, R. O. Arranjos contratuais complexos na transação de cana à usina de açúcar e álcool:: um estudo de caso no centro-sul do brasil. : um estudo de caso no Centro-Sul do Brasil. In: XXXII ENCONTRO DA ANPAD, 32., 2008, Rio de Janeiro. Anais [...] . Rio de Janeiro: Anpad, 2008. p. 1-15.

CONSELHO DOS PRODUTORES DE CANA-DE-AÇÚCAR, AÇÚCAR E ÁLCOOL DO ESTADO DE SÃO PAULO (CONSECANA-SP). Manual de instruções. $5^{\text {a }}$ Edição. Piracicaba, SP, 2006. 112p.

DEDECCA, C. Economia e Mercado de Trabalho. In: DEDECCA, Claudio; MONTALI, Lilia; BAENINGER, Rosana. Regiões Metropolitanas e Pólos Econômicos do Estado de São Paulo: desigualdades e indicadores para as Políticas Sociais.: Estudos Regionais Pólo Econômico de São José do Rio Preto. Campinas: Finep/nepp/nepo/ie Unicamp, 2009. p. 07-22.

DIMAGGIO, P. Cultural Aspects of Economic Organization and Behavior," in: FRIEDLAND, R.; ROBERTSON, A. F. (eds.) Beyond the Market Place: Rethinking Economy and Society, New York, N.Y.: Aldine, 1990.

FARINA, E. M. M. Q; AZEVEDO, P. F; SAES, M. S. M. Competitividade: mercado, estado e organizações. São Paulo: Singular, 1997. 285 p.

FELTRE, C. Coordenação das transações de cana-de-açúcar das usinas sucroalcooleiras no oeste paulista: complementos contratuais e pluralidade. 2013. $191 \mathrm{f}$. Tese (Doutorado) - Curso de Engenharia de Produção, Departamento de Engenharia de Produção, Universidade Federal de São Carlos, São Carlos, 2014. 
.; PAULLILO, L. F.; SOUZA FILHO, H. M. Formas plurais no setor sucroalcooleiro da região centro-sul do Brasil: Os casos das usinas São Manoel-SP e Adecoagro-MS. In: Ménard, C.; Saes, S. M. M.; Silva, V. L. S.; Raynaud, E.. (Org.). Economia das organizações: formas plurais e desafios. 1ed.São Paulo: Atlas, 2014, v. 1, p. 153-166.

FILHO, A. P.; MARIN, J. Contratos de fornecimento de cana-de-açúcar: as assimetrias de poder entre os agentes. Interações (Campo Grande), Campo Grande, v. 13, n. 2, p. 191202, Dec. 2012 . https://doi.org/10.1590/S1518-70122012000200006.

FLIGSTEIN, N. Markets as Politics: A Political-Cultural Approach to Market Institutions. American Sociological Review, 61(4), 656, 1996.

FRANCISCO, E. A. B.; KAPPES, C. Biomas: cerrado brasileiro carece de mais investimentos em práticas sustentáveis. Visão Agrícola, Piracicaba, n. 10, p. 55-57, jan/abr. 2012.

GOIÁS. Governo de Goiás: Clima, vegetação e hidrografia. 2019. Disponível em: https://www.goias.gov.br/index.php/conheca-goias/geografia. Acesso em: 07 abr. 2020.

GRANOVETTER, M. The impact of social structure on economic outcomes". Journal of Economic Perspectives, 19: 33-50, 2005.

GREIF, A. Institutions and the Path to the Modern Economy. Cambridge: Cambridge University Press, 2006.

INSTITUTO BRASILEIRO DE GEOGRAFIA E ESTATÍSTICA - IBGE. Sistema IBGE de Recuperação Automática - SIDRA. Pesquisa agrícola municipal: PAM: Tabelas. Informações sobre culturas temporárias. Área plantada, área colhida, quantidade produzida, rendimento médio e valor da produção das lavouras temporárias. Cana-deaçúcar. 2018 e 2019. Disponível em: <https://sidra.ibge.gov.br/pesquisa/pam/tabelas〉. Acessos em: 01 mar. 2018 e 01 mar. 2020.

KOGA-VICENTE, A.; ZULLO JUNIOR, J.; AIDAR, T. Evolução da produção da canade-açúcar em regiões canavieiras tradicionais e em expansão do estado de São Paulo. In: BAENINGER, R. et al. Regiões canavieiras. Campinas: Núcleo de estudos de população - NEPO/Centro de pesquisas meteorológicas e climáticas aplicadas à agriculturaCEPAGRI/Núcleo de estudos e pesquisas em alimentação- NEPA/UNICAMP, 2013. p. 2940.

LIMA, D. Estrutura e Expansão da Agroindústria Canavieira no Sudoeste Goiano: Impactos no Uso do Solo e na Estrutura Fundiária a Partir de 1990. 2010. 248f. Tese (doutorado) - Universidade Estadual de Campinas, Instituto de Economia, Campinas, SP.

MINAS GERAIS. . Clima, vegetação e relevo. 2019. Disponível em: https://www.mg.gov.br/conteudo/conheca-minas/geografia/clima-vegetacao-e-relevo. Acesso em: 07 abr. 2020. 
NORTH, D. C. Institutions, Institutional Change, and Economic Performance. New York: Cambridge University Press, 1990

PAULILLO, L. F.; VIAN, C. E.; SHIKIDA, P. F.; MELLO, F. T. Álcool combustível e biodiesel no Brasil: quo vadis? Revista de Economia e Sociologia Rural, 45(3): 35.2007.

PEROSA, B.; JESUS, C. M.; ORTEGA, A. C. Expansão da cana-de-açúcar no Triangulo Mineiro e Alto Paranaíba (TMAP) nos anos 2000: o papel da governança. Revista Argumentos (UNIMONTES), v. 14, p. 249-269, 2017.

PEROSA, B. A emergência da governança socioambiental no mercado internacional de biocombustíveis. 2012. Tese (Doutorado) - Curso de Economia de Empresas, Escola de Economia de São Paulo (EESP-FGV), São Paulo.

FILHO, A.P., MARIN, J. Contratos de fornecimento de cana-de-açúcar : as assimetrias de poder entre os agentes. Rev. Interações 13, 191-202, 2012.

PROCANA. Anuário da cana. Centro de Informações Sucroenergéticas. Ribeirão Preto: Procana, 2000/2001; 2015.

QUEIROZ, A. M. Estruturas de governança no complexo agroindustrial sucroalcooleiro goiano. 313 f. Tese (Doutorado) - Curso de Economia, Instituto de Economia, Universidade Federal de Uberlândia, Uberlândia, 2016.

RAMOS, P. Agroindústria canavieira e propriedade fundiária no Brasil. São Paulo: Hucitec, 1999. 245 p. (Economia e Planejamento; 36. Série "Teses e pesquisas"; 21).

SÃO PAULO. Instituto de Economia Agrícola (IEA). Secretaria de Agricultura e Abastecimento. Valor da terra nua. 2018. Disponível em: $<$ http://ciagri.iea.sp.gov.br/nia1/precor_SEFAZ.aspx?cod_tipo=1\&cod_sis=8>. Acesso em: 01 mar. 2018.

SCOTT, W. R. Institutions and Organizations. London: Gafe Publications, 1995.

SHIKIDA P. F. A.; PEROSA B. B. Álcool combustível no Brasil e path dependence. Revista de Economia e Sociologia Rural (SOBER). 2012; 50(2).

VIAN, C. E. F.; BELIK, W. Os desafios para a reestruturação do complexo agroindustrial canavieiro do Centro-Sul. Economia, Niterói (RJ), v.4, n. 1, p. 153-194. Jan/jun. 2003.

WILLIAMSON, O. E. The Economic Institutions of Capitalism. NY: Free Press, 1985. 